\title{
Pharmacogenomics: The Promise of Personalized Medicine for CNS Disorders
}

\author{
Jose de Leon ${ }^{\star, 1,2,3,4}$ \\ ${ }^{1}$ Mental Health Research Center, Eastern State Hospital, University of Kentucky, Lexington, KY, USA; ${ }^{2}$ College of Medicine, \\ University of Kentucky, Lexington, KY, USA; ${ }^{3}$ College of Pharmacy, University of Kentucky, Lexington, KY, USA; ${ }^{4} P$ sychiatry \\ and Neurosciences Research Group (CTS-549), Institute of Neurosciences, Medical School, University of Granada, Granada, \\ Spain
}

This review focuses first on the concept of pharmacogenomics and its related concepts (biomarkers and personalized prescription). Next, the first generation of five DNA pharmacogenomic tests used in the clinical practice of psychiatry is briefly reviewed. Then the possible involvement of these pharmacogenomic tests in the exploration of early clinical proof of mechanism is described by using two of the tests and one example from the pharmaceutical industry (iloperidone clinical trials). The initial attempts to use other microarray tests (measuring RNA expression) as peripheral biomarkers for CNS disorders are briefly described. Then the challenge of taking pharmacogenomic tests (compared to drugs) into clinical practice is explained by focusing on regulatory oversight, the methodological/scientific issues concerning diagnostic tests, and cost-effectiveness issues. Current information on medicine-based evidence and cost-effectiveness usually focuses on average patients and not the outliers who are most likely to benefit from personalized prescription. Finally, future research directions are suggested. The future of 'personalized prescription' in psychiatry requires consideration of pharmacogenomic testing and environmental and personal variables that influence pharmacokinetic and pharmacodynamic drug response for each individual drug used by each patient.

Neuropsychopharmacology Reviews (2009) 34, 159-172; doi: 10.1038/npp.2008.I47; published online 17 September 2008

Keywords: pharmacogenetics; personalized prescription; cytochrome P450; clozapine-induced agranulocytosis iloperidone; metabolic syndrome-genetics

\section{INTRODUCTION}

This review focuses first on the concept of pharmacogenomics and its related concepts (biomarkers and personalized prescription). Next, the first generation of five pharmacogenomic tests used as diagnostic tests in the clinical practice of psychiatry is briefly reviewed. Then the possible involvement of pharmacogenomic tests in the exploration of early clinical proof of mechanism is described by using two of these pharmacogenomic tests and one example from the pharmaceutical industry (iloperidone clinical trials). The initial attempts to use other microarray tests (measuring RNA expression) as peripheral biomarkers for CNS disorders are briefly described. Then the challenge of taking pharmacogenomic tests to clinical practice is explained by focusing on the differences between pharmacogenomic tests and drug evaluation regarding regulatory

${ }^{*}$ Correspondence: Dr J de Leon, Mental Health Research Center, Eastern State Hospital, University of Kentucky, 627 West Fourth Street, Lexington, KY 40508, USA, Tel: +1 859246 7563; Fax: +1 859246 7019, E-mail: jdeleon@uky.edu

Received 28 April 2008; revised 24 July 2008; accepted 25 July 2008 oversight, the methodological/scientific issues, and costeffectiveness issues. Finally, future research directions are suggested. The review seeks to provide more extensive information in those areas not usually described in the psychiatric literature. Several of the discussed topics are usually described in journals not frequently read by psychiatric researchers, including pharmacogenomic, clinical pharmacology, or laboratory journals.

\section{PHARMACOGENOMICS AND RELATED CONCEPTS}

Many psychiatric researchers are familiar with the advances in genetic knowledge and technology; therefore this section has a small subsection covering that area and a more extensive subsection devoted to three concepts with which psychiatric researchers may not be so familiar: pharmacogenomics, biomarkers, and personalized prescription. Pharmacogenomics has been developed within the context of clinical pharmacology. Thus, to understand how pharmacogenomic tests can be transferred to clinical practice, one must be familiar with the history and context 
of pharmacogenomics. The Food and Drug Administration (FDA) has used the concept of biomarkers in discussing how to approve pharmacogenomic tests, therefore the concept of biomarkers is very briefly reviewed. The concept of personalized prescription, as described here, evolved within the context of pharmacogenomics but can be applied beyond pharmacogenomics.

\section{Technological Advances and the Human Genome}

New technologies permitting parallel genetic testing (testing for many genetic variations) developed near the end of the 20th century (Fodor, 1997), and mapping of the human genome was completed in 2000. Both brought hope for a new era in medicine (McKusick, 2001). One of the major technological breakthroughs that allowed the genetic revolution was the introduction of computerized genotyping systems such as the Affymetrix GeneChip (Fodor, 1997). Currently, more advanced forms of these types of DNA microarray technologies (Koch, 2004), including the Illumina BeadArray platform (Steemers and Gunderson, 2007), allow testing more than a half million SNPs at a cost of less than $\$ 1000$ per sample, and further price reductions are in sight.

The importance of these new technologies can be understood when we remember that the human genome may have more than 20000 genes and millions of variations, including the so-called single-nucleotide polymorphism (SNP). More recently, some authors have stressed that other types of genetic variations such as deletions or duplications, the so-called copy number variations (CNVs), may have been neglected (Redon et al, 2006). Moreover, other less common genetic variations such as microsatellite polymorphisms and translocations, inversions, and substitutions may have relevance in pharmacogenomics (Court, 2007). Unfortunately, many of the current platforms and systems used for genotyping pay little attention to CNVs, even though CNVs may be important for pharmacogenomics (Ouahchi et al, 2006) and were first discovered in a pharmacogenetic gene, the cytochrome P450 2D6 (CYP2D6) (Ingelman-Sundberg et al, 2007). Autism (Sebat et al, 2007) and schizophrenia (Walsh et al, 2008) may be associated with CNVs; currently it is not known whether these described CNVs have relevance for treatment or not.

Epigenetics is increasing in importance in psychiatry (Abdolmaleky et al, 2005) and in relationship to psychiatric drug response (Sharma et al, 2006). The relevance of epigenetics for pharmacogenetic response in humans is not well understood (Nebert et al, 2008). It is important to know that it has recently been demonstrated that a fly's drug tolerance to an anesthetic appeared to be mainly caused by epigenetic mechanisms (Wang et al, 2007). Currently it is unclear how epigenetic changes can be tested in the clinical environment, but it has been suggested that pyrosequencing may be a technology that can be used for genetic changes including SNPs, CNVs, and also for methylation status (Marsh, 2007).

\section{History of Pharmacogenomics}

The development of genomic medicine and genetic testing has helped in diagnosing some relatively rare and unusual disorders, but the field of pharmacogenomics is potentially much more important; it has been proposed as the driving force for implementing genetic medicine in primary care (Emery and Hayflick, 2001; Phillips et al, 2001). Vogel (1959) coined the term pharmacogenetics. According to Pirmohamed (2001), pharmacogenetics has been defined as the study of variability in drug response due to heredity and was largely used in relation to genes determining drug metabolism. More recently, the term pharmacogenomics is being used, which is a broader term encompassing all genes in the genome that may determine drug response. The distinction is arbitrary. Both terms are used interchangeably (Pirmohamed, 2001). Roses (2004) made an important distinction between two types of pharmacogenetics. Safety pharmacogenetics is aimed at avoiding adverse drug reactions (ADRs), which are usually called side effects in the psychiatric literature. Efficacy pharmacogenetics is meant to predict response to medication.

\section{The Concept of Biomarkers}

The FDA discussed the approval of pharmacogenomic tests as examples of biomarkers. Many definitions of biomarker exist, one of which is 'a characteristic that is objectively measured and evaluated as an indicator of normal biological processes, pathogenic processes, or pharmacological response(s) to a therapeutic intervention' (Wagner, 2002). There are different types of biomarkers, including pharmacogenomic biomarkers (Court, 2007; Kirkwood and Hockett, 2002).

In the spring of 2005, the FDA (2005) developed guidelines for pharmaceutical companies on the collection and inclusion of genetic information for drug applications. According to the FDA, the results of genetic tests that distinguish allelic variants of two metabolic enzymes, the CYP2D6 and thiopurine $S$-methyltranseferase (TPMT), were considered to be well established and, therefore, valid biomarkers (testing for both enzymes is described later in this article). When submitting an investigational new drug (IND) application to the FDA, pharmaceutical companies must send relevant data on 'valid biomarkers', although other pharmacogenetic data can be submitted voluntarily (Salerno and Lesko, 2005).

\section{The Concept of Personalized Prescription}

A term related to pharmacogenomics and frequently used by lay journals is 'personalized prescription', defined by a Science (1997) editorial as 'tailoring drugs to a patient's genetic makeup'. That editorial in 1997 predicted that personalized medicine will 'soon' reach clinical practice. Other more precise estimates for the generalized use of personalized prescription have been advanced: 2015 by Time magazine (Lertola, 1999) and 2020 by JAMA (Collins 
and McKusick, 2001). If the generalized medical use of personalized prescription is going to occur in 7-12 years, one should notice preliminary steps toward its occurrence in the first generation of pharmacogenetic tests available in psychiatry. Even business journals (Cappell et al, 2005) describe psychiatry (along with oncology) as being at the forefront in the use of pharmacogenomics in medicine.

The concept of personalized prescription is really wider than pharmacogenetics or pharmacogenomics. As a matter of fact, the first versions of two personalized prescription tests, Trastuzumab (Herceptin) and TPMT, did not involve genotyping. Oncology is fortunate to have the availability of tissue samples from tumor cells, allowing testing for very specific drug targets (proteins expressed) within the tumor cells and the use of monoclonal antibodies. Trastuzumab (Herceptin), a humanized monoclonal antibody specific to HER-2/neu, has revolutionized and personalized the management of metastatic HER-2/neu-overexpressing breast cancers (Emens, 2005). As previously indicated, the FDA considers TPMT a 'valid biomarker'. Although the number of subjects with low TPMT activity is small $(<5 \%$ in Caucasians), the leading hospitals treating children with childhood leukemia routinely perform TPMT phenotyping before starting treatment with mercaptopurine, a TMTPmetabolized drug. This is not a genetic test, but a phenotypic test measuring red blood cell enzyme activity (Corominas and Baiget, 2004). The transition from this TPMT phenotyping test to a genotyping test may be challenging for practical reasons. Two views are prominent concerning this transition. The more pessimistic view suggests that using genotyping for TPMT polymorphisms may only account for a small part of the TPTM phenotype (Nebert et al, 2008). Other more optimistic authors, who are trying to encourage the transition from phenotyping to genotyping in the United Kingdom, suggest that practical issues such as familiarity with the test and practice guidelines account for the wide variation in usage of TPTM phenotyping in the United Kingdom, but extensive physician education may be required for the move to genotyping (Fargher et al, 2007). Corominas and Baiget (2004) have stressed that one difficulty in progressing toward TMTP genotyping in this area is the scarcity of drugs metabolized by this enzyme (mercaptopurine and an inactive prodrug, azathiopurine).

\section{Personalized Prescription Including Personal and Environmental Variables}

In the opinion of the author (de Leon, 2007), personalized medicine should include not only the use of tests that may or may not be pharmacogenetic, but the consideration of all scientific information valid for prescribing medication. It must be remembered that physicians have traditionally practiced personalized medicine (Ruaño, 2004) in their attempts to decide the best treatment for each of their patients, even though the term was not used.

Clinicians need to consider genetic, environmental and personal variables when prescribing any medication.
Obviously, the genetic variables can be delineated by pharmacogenomic tests. For some drugs pharmacogenomic variables may be important; for other drugs they may have minimal importance.

Environmental variables such as co-medication or smoking may be much more important than genetic variables for some drugs. As a matter of fact, it is important to develop models to estimate the relevance of environmental variables for psychiatric medications (Botts et al, 2008; de Leon et al, 2005a, 2007b; Diaz et al, 2008). In the clinical environment, a powerful inhibitor can mimic a genetic defect and can also interact with the genetic deficit (de Leon et al, 2007b).

Age and gender may be crucial personal variables in the response to some drugs. They may influence pharmacokinetic and pharmacodynamic factors (de Leon et al, $2008 \mathrm{a}, \mathrm{b})$. In conclusion, the future of 'personalized prescription' in psychiatry requires consideration of pharmacogenomic testing, and also the environmental and personal variables that influence pharmacokinetic and pharmacodynamic drug response for each individual drug used by each individual patient (de Leon, 2007). Recently, Nebert et al (2008) have proposed that the pharmacogenetics of pharmacodynamic genes may be much more complicated than the pharmacogenetics of pharmacokinetic genes. They proposed that pharmacokinetic genes tend to be high-penetrance and predominantly monogenic, whereas pharmacodynamic genes tend to be more polygenic.

\section{FIRST GENERATION OF PHARMACOGENOTIC TESTS FOR CLINICAL PRACTICE IN PSYCHIATRY}

The first generation of pharmacogenomic tests is available for clinical practice in psychiatry. Five pharmacogenomic tests, currently on the market or ready to be introduced in the market, have been included in published articles and are potentially useful in psychiatry. When using peer-reviewed articles to study tests marketed by private companies, one must be aware that some of these companies, as a matter of deliberate practice, do not publish 'proprietary' genetic associations. As a matter of fact, three of the five tests have not published complete details concerning the genes used in them.

There is no computer search strategy in PubMed that provides information on marketed pharmacogenetic tests in psychiatry. Therefore, these five tests were selected in March 2008 as described (de Leon et al, 2008c) from published articles by three authors who had extensively reviewed the pharmacogenetic literature in psychiatry for the past 10 years. That recent article (de Leon et al, 2008c) reviewed these five tests in detail from the point of view of laboratory testing; thus they are described here very briefly (Table 1).

Roche Molecular Systems Inc., developed the first pharmacogenetic test approved by the FDA, The Amplichip CYP 450 Test, which uses Affymetrix technology (Roche, 
2008). The microarray contains over 15000 oligonucleotide probes allowing testing for 20 CYP2D6 alleles, 7 CYP2D6 duplications, and 3 cytochrome P450 2C19 (CYP2C19) alleles (Table 1; de Leon, 2006; de Leon et al, 2006a). CYP2D6 metabolizes several antipsychotic and antidepressant drugs (de Leon et al, 2006b; Kirchheiner et al, 2004). CYP2D6 is highly polymorphic, meaning that more than 60 alleles and more than 130 genetic variations (by combining SNPs and CNVs) have been described for this gene, located on chromosome 22 (Ingelman-Sundberg et al, 2007, 2008). The activity level of the CYP2D6 enzyme, called the CYP2D6 phenotype, can vary widely due to different combinations of the various CYP2D6 alleles. The most important phenotype is the poor metabolizer (PM) phenotype, which does not have active CYP2D6; some subjects have at least three active alleles and are called ultrarapid metabolizers (UMs). CYP2C19 is located on chromosome 10 and is also a polymorphic gene. Alleles with no activity and increased activity are described (Table 1; Wedlund, 2000; Sim et al, 2006). CYP2C19 metabolizes some antidepressants (de Leon et al, 2006b; Kirchheiner et al, 2004). The AmpliChip CYP 450 Test software uses algorithms to predict the four CYP2D6 phenotypes and two CYP2C19 phenotypes.

The Luminex Tag-It ${ }^{\mathrm{TM}}$ Mutation Detection Kit (de Leon, 2006; Melis et al, 2006; Ruaño et al, 2006; Scott et al, 2007) uses the Luminex microsphere-based universal array genotyping platform. The test was originally developed by TMBiosciences which was acquired by Luminex (2008) in 2007. The Detection Kit for CYP2C19 detects the seven CYP2C19 null alleles (Table 1). It appears to be a good system for detecting PMs for both CYP2C19 and CYP2D6. It identifies the wild-type CYP2D6 allele by genotyping 12 tested mutant alleles, as well as gene arrangements associated with deletion and duplication genotypes (Table 1). However, it does not include some of the CYP2D6 low-functioning alleles, has no phenotyping software, and does not specify which allele may be duplicated (de Leon, 2006). The Detection Kit for CYP2C9 detects five variants (Table 1; Ruaño et al, 2006). CYP2C9 has almost no involvement in antipsychotic metabolism but may have a minor involvement for some antidepressants (Black et al, 2007). It is possible that CYP2C9 polymorphisms may be important for patients who are deficient in other CYPs and are taking antidepressants (Ruaño et al, 2007a).

The possible applications of CYP2D6 and CYP2C19 in psychiatry have been reviewed in prior articles (de Leon et al, 2006b, 2008c), including facilitating treatment with some antipsychotic and antidepressant drugs, particularly those with a narrow therapeutic window and which are highly dependent on either of these two enzymes for their metabolism (de Leon, 2007). Obviously, not all psychiatric drug therapy will be improved by this testing; as a matter of fact, the selective serotonin reuptake inhibitor (SSRI) drugs may not be good candidates for CYP genotyping based on currently available information (Evaluation of Genomic Applications in Practice and Prevention (EGAPP) Working Group, 2007; Katsanis et al, 2008). As a matter of fact, pharmacological knowledge predicts that SSRIs are not good candidates for safety pharmacogenomics; they exhibit no linear relationship between dosage and plasma concentration, wide ranges between therapeutic and toxic doses, and powerful CYP inhibition from some SSRIs (de Leon, 2007, 2008).

Arranz et al (2000a) generated a lot of interest when they designed a system combining variants in the gene coding for 5-HT2A, 5-HT2C, and H2 receptors and for the serotonin transporter 5-HTT that predicts clozapine response, as this was one of the first attempts to develop a pharmacogenetic test in psychiatry. Other authors were not able to replicate the predictive results of the test in patients from different clinical settings (Arranz et al, 1998, 2000b; Schumacher et al, 2000). The UK company LGC (2008) offers an improvement of this test, incorporating a number of yet undisclosed genetic variants.

Two other pharmacogenetic tests that will be described in the next section are a pharmacogenetic test for clozapineinduced agranulocytosis, the PGxPredict:CLOZAPINE test (PGxHealth, 2008), and a test for metabolic syndrome, the PhyzioType system (Genomas, 2008).

This article does not review all pharmacogenomic studies in psychiatry, but focuses on available or soon-to-be available pharmacogenomic tests that can be used in the clinical environment and can help in the early exploration of clinical proof of mechanism. In the past few years, the STAR ${ }^{\star D}$ study (McMahon et al, 2006; Paddock et al, 2007; Perlis et al, 2008; Peters et al, 2008) and other studies (Binder et al, 2004; Uhr et al, 2008) have led to a boom in pharmacogenomic studies of antidepressants. However, pharmacogenomic tests for antidepressant response will apparently not be available for clinical use soon. Genotyping for serotonin receptor and transporter variations are offered by two US laboratories (Mayo Clinic Laboratory, 2008; Pathway Diagnostics, 2008) but they have not published data supporting their use and the literature reflects the conflicting results of these gene associations with serotonin receptors (Kirchheiner et al, 2004; Serretti and Artioli, 2004), although the association with the serotonin transporter looks more promising (Serretti et al, 2007).

\section{POSSIBLE INVOLVEMENT OF PHARMACOGENOMIC TESTS FOR EXPLORING EARLY CLINICAL PROOF OF MECHANISM}

\section{Pgxpredict: CLOZAPINE Test}

Clozapine treatment was associated with a risk of agranulocytosis estimated at $1-2 \%$, but required weekly white blood cell monitoring and a national registry in the US have decreased the estimate to $0.4 \%$ (Honigfeld et al, 1998). In the past, clozapine agranulocytosis was associated with HLA variants in Ashkenazi Jews (Lieberman et al, 1990). 
Genaissance Pharmaceuticals Inc. (a pharmacogenetics company) developed a genetic test to predict clozapineinduced agranulocytosis. Genaissance Pharmaceuticals Inc. was acquired by Clinical Data (a diagnostic company) in 2005. The pharmacogenetic branch of Clinical Data (called PGxHealth) named this test PGxPredict : CLOZAPINE, but it is not currently described on their website (PGxHealth, 2008). The author contacted a company representative, who explained the company has 'opted to stop offering' the first generation of the test, but she explained that PGxHealth 'will continue to focus our resources on developing a second generation test.' The opinion of this author (encouraged by a reviewer request) is that the formerly available version of the test was not very helpful as it did not eliminate the need for blood monitoring in those with negative results, and patients with positive results may not have had options besides clozapine, as clozapine in the United States is mainly considered after trying all other antipsychotics.

The interesting aspect of this test is that only two of the five genes described as associated with clozapine-induced agranulocytosis were from the HLA complex (Malhotra et al, 2005). The three yet-unpublished genes may be excellent examples of leads for future proof of mechanism studies. If these genes are replicated in other studies, they may help in understanding the mechanism behind the pathophysiology of clozapine-induced agranulocytosis.

\section{PhyzioType System}

Metabolic syndrome is much more frequent in psychiatric patients taking antipsychotics than in the general population (McEvoy et al, 2005; Susce et al, 2005), to the point that it is considered an epidemic (Reist et al, 2007).

Genomas (2008), a personalized medicine company, has developed a patented system (Patent Application Publication US 2006/0234262A1) called the PhyzioType system (Ruaño et al, 2007b; de Leon et al, 2008c). The system uses an ensemble of DNA markers from several genes coupled with a biostatistical algorithm to predict an individual's risk of developing ADRs, including the antipsychotic-induced metabolic syndrome (Table 1 ).

The majority of antipsychotics (particularly some of the so-called atypical antipsychotics, but also some of the typicals) increase the risk of obesity, probably by increasing appetite, or by blocking brain receptors, including $\mathrm{H}_{1}$ and 5- $\mathrm{HT}_{2 \mathrm{C}}$ (de Leon and Diaz, 2007; Kim et al, 2007; Meyer and Koro, 2004; Newcomer and Haupt, 2006). Some of the atypical antipsychotics (particularly olanzapine and clozapine) also appear to directly interfere with glucose (de Leon and Diaz, 2007; Newcomer and Haupt, 2006) and lipid metabolism (de Leon and Diaz, 2007; de Leon et al, 2008c, d; Meyer and Koro, 2004). It is possible that some other antipsychotics besides olanzapine and clozapine, particularly quetiapine and phenothiazines such as chlorpromazine, also directly interfere with lipid metabolism (de Leon and Diaz, 2007; de Leon et al, 2008d; Meyer and Koro, 2004) and cause hyperlipidemia in the absence of obesity or when controlling for the effects of obesity (Birkenaes et al, 2008; de Leon et al, 2007a; Markham-Abedi and de Leon, 2006).

The PhyzioType system was used as proof of mechanism to study genes that may serve as good candidates for future studies of the direct effects (not explained by obesity) of some antipsychotics on hyperlipidemia. Known physiological mechanisms were supported for three associations found in patients taking olanzapine, quetiapine, or chlorpromazine in the acetyl coenzyme A carboxylase $\alpha$-SNP (rs4072032) in the hypertriglyceridemia model, and for the neuropeptide $\mathrm{Y}(\mathrm{rs} 1468271)$ and $\mathrm{ACC} \beta$ (rs2241220) in the hypercholesterolemia model (de Leon et al, 2008d). Thus, in vitro studies could be used to explore interference in lipid metabolism from clozapine, olanzapine, quetiapine, or chlorpromazine (or molecules with a similar chemical structure, such as mirtazapine; de Leon, 2008). To verify the SNPs suggested by the DNA as proof of mechanism, these molecules should interfere with lipid metabolism more so than other antipsychotic molecules. Moreover, they should specifically interfere with fatty acid metabolism at the ACC $\alpha$; this would verify a possible mechanism indicating the reason some antipsychotics may cause hypertriglyceridemia. The greater interference of these molecules than other antipsychotic molecules with NPY or $\operatorname{ACC} \beta$, or a related mechanism involved in cholesterol synthesis regulation, would verify a possible mechanism indicating the reason some antipsychotics may cause hypercholesterolemia. These in vitro studies have not been performed.

\section{THE USE OF PHARMACOGENOMIC TESTS BY PHARMACEUTICAL COMPANIES FOR EXPLORING EARLY CLINICAL PROOF OF MECHANISM}

Pharmaceutical companies are using DNA microarrays in their clinical trials and are extensively using biomarkers in drug development. Several review articles written by scientists working in pharmaceutical companies describe their potential (Ferentz, 2002; Kirkwood and Hockett, 2002; Lesko and Atkinson, 2001). However, there are no published examples of the results of the use of DNA microarrays in drug marketing for psychiatric drugs, except for iloperidone, which is described next.

\section{lloperidone and DNA Pharmacogenomic Testing}

Iloperidone is a mixed 5-HT2A and D2 antagonist developed for the potential treatment of schizophrenia (Albers et al, 2008; Hesselink, 2002). Iloperidone was developed by Hoechst Marion Roussel. After reaching Phase II trials, the company announced in May of 1996 that it had discontinued further development, and in January of 1997 it licensed the compound to Titan Pharmaceuticals. In April of 2001 Titan executed a new development and commercia- 
TABLE 1: Pharmacogenomic tests that have published information and are available for clinical use, have been available or are expected to be available soon (This table reflects the current personal views of the author and may be influenced by his biases and lack of internal company knowledge).

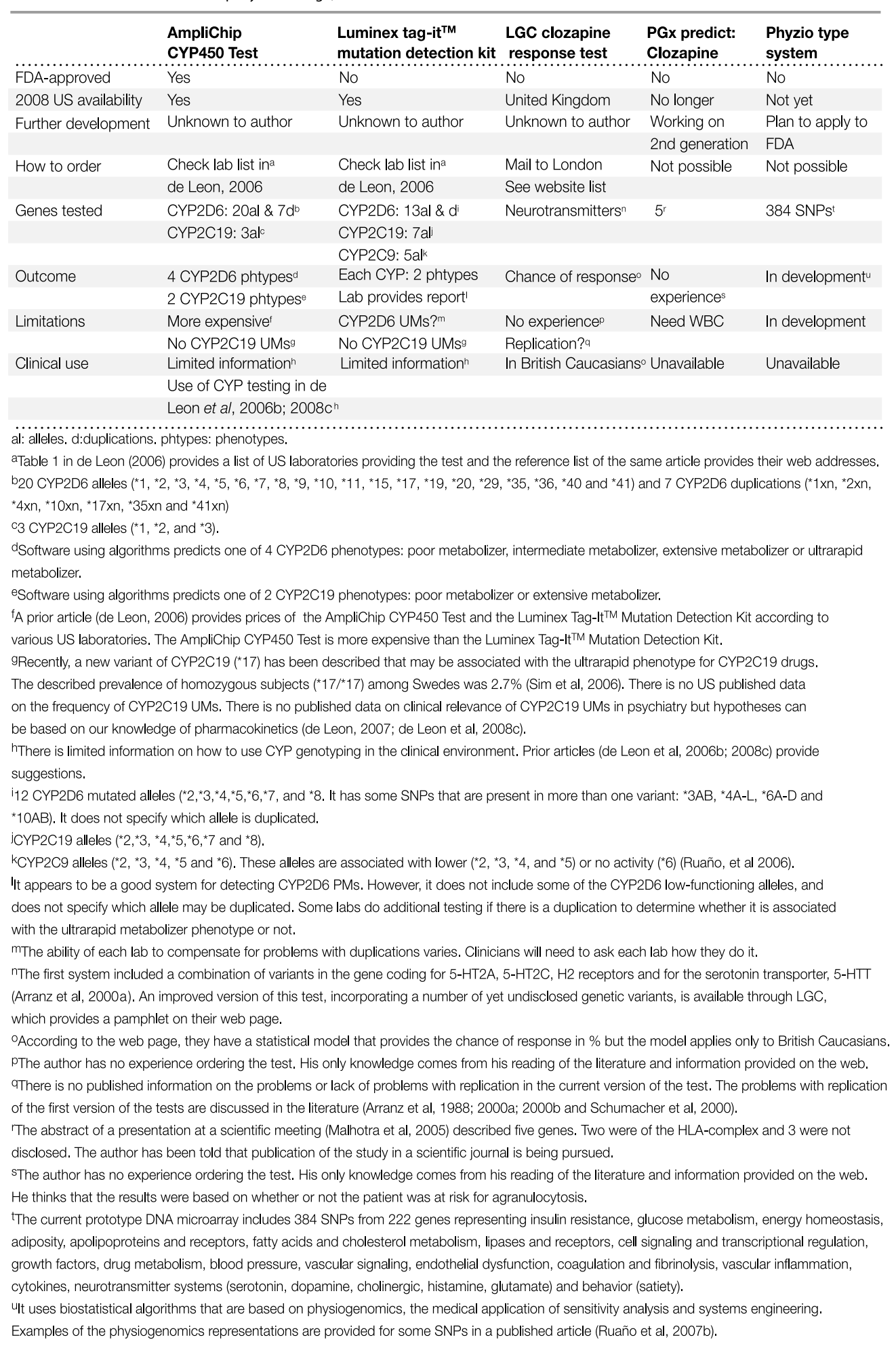

lization agreement with Novartis, which predicted a possible launch in 2002 (Hesselink, 2002). This was further revised several times (Hesselink, 2002) and, finally, Vanda Pharmaceuticals acquired the drug. In 2007 Vanda Pharmaceuticals sent the FDA a new drug application
(NDA) for iloperidone. On July 28, 2008, it announced that the FDA required more studies (Vanda Pharmacueticals, 2008).

Preliminary research that tested only one CYP2D6 null allele suggested that iloperidone is associated with a QTc 
prolongation that is related to drug levels and CYP2D6 metabolism; therefore the prolongation of QTc in CYP2D6 PMs (Nnadi and Malhotra, 2008) may be avoided simply by reducing iloperidone dosing in CYP2D6 PMs. Lavedan et al (2008a) described an attempt to use a SNP at the ciliary neurotrophic factor (CNTF) polymorphism to predict schizophrenia symptom improvement in an iloperidone clinical trial. CNTF is a multifunctional cytokine that supports cell survival and/or differentiation (Sendtner et al, 1994). In the brain, CNTF may regulate several neurotransmitters including dopamine, serotonin, and acetylcholine, and may have neuroprotective effects (Lavedan et al, 2008a; Tolosano et al, 1996).

More recently, genome-wide associations have been published identifying six SNPs associated with QTc prolongation (Volpi et al, 2008) and other six SNPs associated with efficacy (Lavedan et al, 2008b), including the neuronal PAS domain protein 3 gene (NPAS3). The main question remaining after reading these articles is whether any of these genetic associations will be replicated in other research samples and, more importantly, in the clinical environment. Nebert et al (2008) proposed that high significance in one genome-wide association study may not be that important; replication is the most important requirement in establishing a positive association. At any rate, it is currently unknown whether the attempted rescue of iloperidone using pharmacogenomic testing will be successful or not. It is interesting that the rescue attempt was conducted by a small company funded by a pharmacogenomic expert who left the last large pharmaceutical company that decided not to pursue the marketing of this drug.

\section{Lack of Enthusiasm Among Pharmaceutical Companies for Pharmacogenomic Testing}

Pharmaceutical companies have not embraced pharmacogenomic testing in clinical practice. As a matter of fact, the experience of this researcher (de Leon et al, 2006a) and others (Weinshilboum and Wang, 2004), and of reports from an FDA official (Cappell et al, 2005), is that the large pharmaceutical companies typically distrust pharmacogenomic testing. Their current business model assumes drug approval on the basis of an average dosage recommendation for an average patient. Thus, the practice of treating some patients with alternative drugs would create narrower market niches (Danzon and Towse, 2002), and genotyping and treating some with an alternative dosage would complicate the package insert relative to competing drugs (de Leon, 2006; de Leon et al, 2006a). If a drug is approved with pharmacogenomic testing as a requirement, the marketers of previously approved competing drugs will surely remind physicians that their drugs do not have such a requirement in their prescription package, but the new drug does.

In the case of new drugs, the pharmaceutical companies' current stance toward pharmacogenetics appears to be leading to the elimination of drugs metabolized mainly by CYP2D6 as candidates for marketing (Ingelman-Sundberg et al, 2007; Sadee, 2002; Weinshilboum and Wang, 2004) as a significant number of Caucasians (10-15\%) may have the extreme phenotypes PM or UM. There are no clear incentives for pharmaceutical companies to incorporate new pharmacogenomic knowledge of already marketed drugs. The issue gets very complicated when the drugs are generic, as companies producing generic drugs have very low margins. Some authors have indicated that a more aggressive role on the part of the FDA is needed to expedite the use of pharmacogenomic testing in the drug approval process (Weinshilboum and Wang, 2004).

\section{OTHER MICROARRAY TESTS: THE UNCERTAINTY OF PERIPHERAL BIOMARKERS FOR CNS DISORDERS}

As blood is easily available, there has been interest in using microarray tests to explore transcriptional profiles (RNA activity) as possible biomarkers and/or tools in pharmacogenetic studies (Baird, 2006; Burczynski and Dorner, 2006). These attempts are in the early stage, even in the promising area of inflammatory diseases, and there are major methodological questions (Baird, 2006; Burczynski and Dorner 2006). In psychiatry, several attempts have been made to use blood expression as a biomarker in the diagnosis of psychiatric disorders, including schizophrenia (Bowden et al, 2006; Tsuang et al, 2005) and post traumatic stress disorder (Segman et al, 2005). It is too early to predict the value of this type of biomarker, as there is limited data to support the use of blood cell expression to ably represent brain cell expression (Glatt et al, 2005), although it appears somewhat promising in other brain disorders in which we have a better understanding of the pathophysiology, such as Parkinson's disease (Scherzer et al, 2007).

Current psychopharmacological knowledge suggests that peripheral markers, such as blood expression, may not be good biomarkers in pharmacogenetic studies for measuring brain neuron response to psychiatric treatments. Transporters at the blood-brain barrier may be important in the response to psychiatric drugs. The P-glycoprotein, P-gp, is one such transporter. Several, but not all, antidepressants (El Ela et al, 2004) and antipsychotics (Boulton et al, 2002) are substrates of this transporter to different degrees, suggesting that there may be differences between blood and brain concentrations, at least with some of these compounds. Moreover, there may be differences between a compound and its metabolites and, in the case of risperidone and its metabolite (Wang et al, 2004), this may contribute to differences in their side effects and dosing (de Leon et al, 2007b, 2008b).

\section{THE CHALLENGE OF APPLYING PHARMACOGENOMIC TESTS IN CLINICAL PRACTICE}

Psychiatric researchers may be familiar with how new psychiatric drugs are taken to the market, but 
pharmacogenomic tests are not drugs and the process is remarkably different for putting a new diagnostic test on the market. This section focuses on the regulatory oversight, the methodological/scientific issues concerning diagnostic testing, and cost-effectiveness.

\section{Regulatory Oversight}

In the United States, pharmacogenomic testing (or biomarker testing) is subject to two types of regulations (Swanson, 2002). Quality standards for clinical laboratories in the United States have their roots in the Clinical Laboratory Improvement Amendments (CLIA), which are administered by the Centers for Medicare \& Medicaid (CMS). Accreditation is obtained through accreditation organizations such as the College of American Pathologists (CAP) and the Joint Commission on Accreditation of Healthcare Organizations (JCAHO) or by state Health Departments. Accrediting organizations adopt guidelines and policies that go beyond the generalities of regulatory requirements and promote specific, best laboratory practices across all processes and require well-defined quality assurance programs. Thus, accreditation by CAP or JCAHO assures full compliance with CLIA regulations plus achievement of an overall high standard of laboratory practice (Swanson, 2002).

Good laboratory practice (GLP) regulations that were originally to govern animal toxicological studies are enforced by the FDA. These FDA regulations govern the testing of new medical devices in humans and do not specifically apply to clinical laboratories, but the data generated by clinical laboratories on specimens derived from clinical drug trials must be presented in final study reports and ADR documents submitted to the FDA (Swanson, 2002).

The development of pharmacogenomic testing has brought about a convergence of laboratories from GLPregulated, CLIA-regulated, and basic research settings (Swanson, 2002). As a matter of fact, the FDA has been one of the main supporters of pharmacogenetic testing in the United States in recent years. The FDA has progressively set some new recommendations. In 2005, it provided guidance for the drug industry regarding pharmacogenetic data submission (FDA, 2005) and introduced the idea of a voluntary data submission program (Orr et al, 2007). Later on, the FDA (2008) issued draft guidance for 'In Vitro Diagnostic Multivariate Index Assays (IVDMIAs)' indicating an intent to require IVDMIAs to meet premarket and postmarket device requirements under FDA regulations. DNA microarrays are IVDMIAs.

SACGHS (2006), which advises the Secretary of Health and Human Services (HHS), reviewed the coverage and reimbursement of genetic testing. The Committee considered three aspects of pharmacogenomic test evaluation including analytic validity, clinical validity, and clinical utility. Analytic validity addresses accurate and reliable measurement of the genotype, clinical validity the ability to detect or predict the associated disorder, and clinical utility the risks and benefits of test use. In general, analytic validity is quite high for chip- and bead-based genomic methodologies with sensitivity and specificity in excess of $99 \%$.

It is apparent that advances in clinical genetic testing have so far outpaced the regulatory framework needed to assure its safety and effectiveness (Javitt, 2007; Katsanis et al, 2008). Some laboratories have marketed genetic testing directly to patients (Katsanis et al, 2008). Javitt (2007) explained that the success of genetic testing depends, therefore, on the development of a coherent framework for oversight which provides both adequate assurance of the safety and effectiveness of genetic tests and an equitable and stable regulatory playing field. The main goal of pharmacogenomics is to help prescribe medication in a more personalized way. Thus, there is no doubt in the mind of the author that pharmacogenomic testing should be ordered by the physicians who will be prescribing the medications. As indicated before, well-trained physicians are needed to implement pharmacogenomic testing and personalized prescription in clinical practice. To that end, there have been several recommendations concerning the provision of better pharmacogenomics education for students of medicine (Gurwitz et al, 2003) and other clinical professions (Gurwitz et al, 2005).

\section{Methodological/Scientific Issues in Diagnostic Testing}

Some pharmacogenomics review articles (Grossman, 2007) insist on suggesting that the model developed by pharmaceutical companies, that of introducing a new drug into the market by sponsoring double-blind randomized trials, should be used as the ideal evidence-based model for introducing pharmacogenomic testing into the market. This approach does not appear to be reasonable from the scientific point of view, as pharmacogenomic tests are not drugs which need to be proven effective in the controlled environment of a clinical trial with randomized and placebo design; they are diagnostic tests that must be proven useful in the complex clinical environment.

Despite these obstacles, the potential benefit of personalized prescription for some individuals is great. A recent large multicenter study using a randomized double-blind prospective design that was funded by a pharmaceutical company demonstrated that pharmacogenetic testing can be used to prevent a serious immunological ADR (Mallal et al, 2008). Although the design was simple, it eliminated the outliers, who were not included in the study.

A major unresolved conceptual issue is that randomized clinical trials provide an average dose for an average patient whereas patients at the upper and lower ends of the response distribution (extreme outliers) tend to be ignored. These are precisely the patients who most need personalized prescription and pharmacogenomic testing. If these subjects are quite rare, it is not easy to conduct prospective wellcontrolled studies of them. Some subjects lack both CYP2D6 and CYP2C19, which metabolize most antidepressants. 
After identification, they can be correctly treated using our current pharmacological knowledge (Johnson et al, 2006). Large studies of these 'double' PMs are not likely to occur as they are $<1$ per 1000 in each race; to identify 30 of them a sample of approximately 50000 patients taking antidepressants would be needed (de Leon, 2007).

Feinstein and Horwitz (1997) have indicated that the evidence-based medicine approach does not address the issue of diagnostic tests. Only very recently has the evidence-based medicine approach considered the peculiarities of the new diagnostic tests, which include concepts such as pharmacological mechanism response, linkage to clinical outcome or toxicity, replication/confirmation, and analytic validation (Altar et al, 2008).

Traditionally, the scientific properties of diagnostic tests have been assessed using the concepts of sensitivity (true positive rate) and specificity (true negative rate), which can be used to estimate other derived measures such as accuracy, the likelihood ratio of a positive/negative test, and the positive/negative predictive value (Greenhalgh, 1997; Deeks, 2001). In the clinical environment, sensitivity and specificity are influenced by the frequency of the disorder; thus, consideration of other measures, particularly the likelihood ratio, may be better for assessing the value of a diagnostic test (Trenti, 2003). Recently, the number needed to screen has been proposed as a better measure for assessing diagnostic tests but it requires a design that includes an intervention; therefore the number needed to screen reflects both the performance of the diagnostic test and the intervention (Rembold, 1998). There is no published data on the number needed to screen for any of the five pharmacogenomic tests in psychiatry. A prior article described the limited data available on sensitivity/ specificity, predictive values, and likelihood ratios in the clinical studies of these five tests (de Leon et al, 2008c).

To understand the levels of complexity of a diagnostic test, the following discussion is limited to the sensitivity and specificity aspect. At first glance, defining the sensitivity and specificity of a pharmacogenetic test would seem simple. However, one can think of several levels of sensitivity and specificity: in the determination of genetic variation in the laboratory, in the determination of genetic phenotype in the laboratory and of genetic phenotype in the clinical environment. These three levels of sensitivity/ specificity (which can be called analytic validity, clinical validity and clinical utility; SACGHS, 2006) have previously been discussed concerning the AmpliChip CYP450 Test (de Leon, 2006).

The first level of sensitivity/specificity (analytic validity) refers to the ability of the pharmacogenomic test to detect the different alleles. This can be understood using the highly polymorphic CYP2D6 gene as an example. More than 130 genetic variations (by combining SNPs, gene deletion, and multiplications) have been described for this gene, that combined, provides more than 60 alleles (IngelmanSundberg et al, 2007; Ingelman-Sundberg et al, 2008). What is the minimal number of genetic variations that may be needed to detect frequent variations? Which variations do not need to be routinely tested? There is no agreement in the literature and the answer depends on the racial composition of the population (Cai et al, 2006). Statistical attempts have been made to try to use a few genetic variations to detect CYP2D6 genotyping; the results are not bad from the scientific point of view (Sabbagh et al, 2008), but cannot be used for treating patients in whom a high level of sensitivity/specificity is required.

The second level of sensitivity/specificity (clinical validity) refers to the translation of the test results to clinically meaningful outcomes; in the case of CYP2D6, of different phenotypes. A major limitation of this step is our knowledge of the gene or genes of interest. The genotype/ phenotype associations of CYP2D6 were first studied more than 15 years ago, but important new variations that eliminate gene function are still being described in Black Africans and African-American subjects (Gaedigk et al, 2002). In a US population and a world population with racial admixture (Suarez-Kurtz and Pena, 2006), our limited knowledge of how to extrapolate genetic variations across races to promote clinically relevant gene functioning may become a major limiting factor in the implementation of pharmacogenomics in the clinical environment.

The third level of sensitivity/specificity (clinical utility) refers to the ability of a phenotype (eg CYP2D6 PM) to make clinical predictions. This is not a reflection of the test but rather of the clinical populations studied. In the case of the CYP2D6 PM phenotype, the ability to predict ADRs is contaminated by the presence of confounding environmental factors. Some antidepressants, such as paroxetine and fluoxetine, may inhibit CYP2D6 completely, making phenocopies of CYP2D6 PMs. The dosage of the CYP2D6 substrate may also influence the ability of the CYP2D6 PM phenotype to predict ADRs. Finally, the CYP2D6 drugs may influence the ability to predict ADRs. One of the CYP2D6 alleles $\left({ }^{*} 17\right)$ frequent in Blacks and African Americans has traditionally been associated with lower CYP2D6 function for several CYP2D6 substrates (Wennerholm et al, 2002), but appears to have normal activity for risperidone (Cai et al, 2006). In a naturalistic risperidone study the CYP2D6 PM phenotype had low sensitivity for predicting risperidone ADRs (9-16\%) but reasonable specificity (2/3 to $3 / 4$ ) (de Leon et al, 2007a). This means that only a small number of risperidone ADRs are explained by this genetic variation, which is associated with a missing liver enzyme that metabolizes risperidone. The sensitivity/specificity value reflects the relevance of the genetic variation in reference to the sample but says little about the individual who is a CYP2D6 PM. In that study, the CYP2D6 PMs had 3-6 times more risk (measured using odds ratios) of having risperidone ADRs (de Leon et al, 2005a, b).

The results from this risperidone study refer only to a specific sample in a specific clinical environment. These properties may vary in other samples in other clinical environments, which brings to mind the concept of generalizability, a major problem for prediction tests 
(Justice et al, 1999). Only predictors that are strong and consistent are generalizable to different clinical settings. These concepts can be expressed in statistical terms but have not been sufficiently explored in the medical literature. Egmont-Petersen et al (1997) used the terminology of signal-to-noise ratio (from electrical engineering) to define the robustness of a diagnostic test. The idea is that there is 'noise' which makes the proper classification of each case (the 'signal') difficult. The 'noise' can come from the laboratory (eg a problem related to technology or the interpretation of genotypes) or from the clinical environment (eg changes in phenotype due to the effects of environmental confounders in genotypes, drug dose variability, and racial variability in genotype-phenotype relationships). Grosse et al (2007) have stressed that for diagnostic tests randomized clinical trials may present the challenge of needing huge sample sizes as the contribution of the diagnostic test to the outcome may be very small and difficult to separate from the confounding factors.

The development of technologies that permit massive and generalized genetic testing should be heralded as a breakthrough, but at the same time as a major methodological challenge, as we currently lack the statistical techniques to determine which of the thousands of genetic variations that can currently be examined may be relevant and generalizable to different clinical settings, or symptom/phenotypespecific (Arranz and de Leon, 2007).

\section{Cost-Effectiveness}

Ideally, the introduction of pharmacogenomic tests in the clinical environment should include cost-effectiveness studies (Wedlund and de Leon, 2001). However, one needs to acknowledge that many medical advances are not costeffective. In psychiatry, the switch from typical to atypical antipsychotics has been associated with a remarkable increase in drug costs (probably by a factor of 6) without reduced expenses in other types of medical care (Duggan, 2005). Moreover, diagnostic tests such as drug blood levels are used in clinical practice with no cost-effectiveness studies (Touw et al, 2005).

The science of cost-effectiveness for diagnostic tests is in its infancy (Grosse et al, 2007; Van den Bruel et al, 2007). After discussions with scientists who plan the marketing of pharmacogenetic tests, the author has the impression that there are two major differences between the cost-effectiveness of a pharmacogenetic test and of a drug; the benefits are much lower and the uncertainties much larger for pharmacogenetic tests. To understand these major differences, it is helpful to review the similarities as well. Both drugs and diagnostic tests are ordered by physicians. In the case of a drug, once there is a physician willing to prescribe, the only question left is whether the patient and/or a third party will pay for the medication as medications can easily be purchased at pharmacies. Diagnostic tests are different in that, even if the physician is willing to order it, he or she must find a laboratory that has purchased the appropriate equipment and supplies and is prepared to run the specific diagnostic test. Patients rarely have to pay for diagnostic tests, although they may pay for their own medications. Diagnostic tests, particularly pharmacogenetic tests, are performed once in a lifetime, whereas a patient taking a drug may take it for days or years, thus providing ongoing revenue for the manufacturer.

As far as the author knows, the market for diagnostic testing is much smaller than for drugs and provides no possibilities for the blockbuster revenues seen with some drugs. The uncertainties of marketing a diagnostic test are larger because the FDA has a sophisticated system in place for approving drugs, but has only recently become interested in diagnostic tests, due to the relevance of pharmacogenetic testing. Drugs are subject to a sophisticated scientific process for approval, including randomized clinical trials, but for diagnostic tests, randomized clinical trials may not be indicated at all or may be difficult (Grosse et al, 2007). Therefore, the pharmacogenetic companies are faced with smaller benefits and more risks than the much more powerful pharmaceutical companies and, as a rule, lack the resources of the big drug companies.

More cost-effectiveness studies of pharmacogenetic studies in psychiatry are needed, as only a few exploratory studies have been completed (Chou et al, 2000; Perlis et al, 2005). The author believes that these cost-effectiveness studies may need to focus on outliers more than on average patients.

\section{FUTURE RESEARCH DIRECTIONS}

Pharmacogenetics appears to be progressing faster in psychiatry than in other areas of medicine, with the possible exception of oncology. Oncology is fortunate in having easy access to tissue, which allows for various types of testing that can be used to personalize prescriptions. As a matter of fact, some of the tests used in the clinical practice of oncology for personalizing prescriptions are not pharmacogenomic tests. The lethality of the oncological diseases, combined with the high toxicity and the high cost of oncological drugs, may make personalized prescription in oncology cost-effective. As a matter of fact, CYP2D6 genotyping may be getting a second life in oncology as tamoxifen may not have protective effects against breast cancer in CYP2D6 PMs (Beverage et al, 2007).

Recent pragmatic trials in psychiatry, such as the Clinical Antipsychotic Trials of Intervention Effectiveness (CATIE), have demonstrated what clinicians know: that the first psychiatric drug a psychiatrist prescribes for a patient may not be the best choice for an individual patient, and that multiple drug trials are commonly needed before an antipsychotic is found that is adequately efficacious, safe, and acceptable for an individual (Stroup et al, 2007). Therefore, the future of 'personalized prescription' in psychiatry, with better pharmacokinetic and pharmacodynamic genetic testing, could ultimately lead to better clinical 
outcomes in patients taking psychiatric drugs. Studies such as CATIE may help clinical researchers reduce their focus on the current approach used by pharmaceutical companies, which is to try to find the best drug for the average patient. The 'average' patient may indeed be uncommon for some drug prescribed to patients with multiple comorbidities and comedications (de Leon et al, 2005b).

This review briefly describes the pharmacogenomics tests that are on the market, have been on the market or are ready to be marketed and for which published information is available. The laboratory aspects of this first generation in psychiatry, which includes five pharmacogenomic tests, have been described in more detail elsewhere (de Leon et al, 2008 c) and should give rise to a second generation of more sophisticated studies of tests in the next 5-10 years, leading hopefully to the more generalized use of pharmacogenomic testing by psychiatrists. Two of these five tests have been briefly described in reference to how they can be used as proof of mechanism. The pharmaceutical companies appear to be extensively exploring pharmacogenomics in drug development and as proof of mechanism in clinical trials. As an example, the use of pharmacogenetic tests used in iloperidone trials is briefly described.

The area of biomarkers, including biomarkers that are not pharmacogenetic biomarkers, is receiving much attention by the industry, particularly regarding its potential for personalizing prescriptions (Wagner, 2008). Initial steps in using microarray testing (particularly for RNA expression) of blood in psychiatric patients have been taken, but it is uncertain whether these tests will have clinical relevance in the near future. A new wave of tests and disciplines, including transcriptomic, proteomic, and metabolomic tests, are being developed, but it is unknown when they will be ready for clinical practice. Similarly, epigenetic knowledge and methods of assessment do not appear ready for the clinical environment.

The challenges of introducing pharmacogenomic tests in clinical practice have been described in this review with particular focus on changing regulatory oversight, the methodological/scientific issues, and the unresolved issue of cost-effectiveness. One key to a successful future for pharmacogenetic testing is the establishment of an appropriate level of oversight by regulatory agencies. Psychiatric researchers have a crucial role as well, that of expanding the very limited evidence that exists for the use of pharmacogenomic testing in psychiatry. Clinical psychiatrists need to balance the responsibility of treating individual patients, some of which may not be average, with the information that we have on the average patient. Current information related to medicine-based evidence and the cost-effectiveness of pharmacogenomic testing usually focuses on the average patients and not on the outliers who are the most likely to benefit from personalized prescription.

New well-trained psychiatrists are needed in the effort to personalize prescription in psychiatry. These sophisticated psychiatrists must incorporate not only pharmacogenomic testing but also scientific knowledge in other areas such as environmental variables (co-medications) and personal characteristics (gender and age). In conclusion, the future of 'personalized prescription' in psychiatry requires consideration of pharmacogenomic testing, and also the environmental and personal variables that influence pharmacokinetic and pharmacodynamic drug response for each individual drug used by each individual patient. Wolf et al (2000) predicted that in the future it might be considered unethical not to utilize pharmacogenetic testing to avoid exposing individuals to ADRs. But realizing that promising future requires extensive analytical, clinical, and regulatory advances.

\section{ACKNOWLEDGEMENTS}

I thank Gualberto Ruaño, $\mathrm{MD}, \mathrm{PhD}$, of Genomas Inc., for discussion; Lorraine Maw, MA, for editorial assistance; and Roy $\mathrm{H}$ Perlis, MD, MSc, along with two anonymous reviewers, for providing very helpful suggestions for improving the article.

\section{DISCLOSURE/CONFLICT OF INTEREST}

Dr de Leon is currently a co-investigator in a NIH Small Business Innovation Research Grant 2 R44 MH073291-02 'DNA Diagnostics for Minimizing Metabolic Side-Effects of Antipsychotics' awarded to Genomas Inc. In the past 3 years (since 1 July 2005), Dr de Leon has received researcherinitiated grants from Roche Molecular Systems Inc., and from Eli Lilly (the latter as co-investigator) and was on the advisory board of Roche Molecular Systems Inc. (2006). He personally develops his presentations for lecturing and has never lectured using any pharmaceutical company presentations. In the past three years (since 1 July 2005) his lectures have been supported seven times by Roche Molecular Systems Inc. (once in 2005 and six times in 2006), twice by Eli Lilly (two in 2006), once by Janssen (2006), and once by Bristol-Myers Squibb (2006). He has never been a consultant and has no other financial arrangements with pharmacogenetic or pharmaceutical companies nor owns any of their stocks.

\section{REFERENCES}

Abdolmaleky HM, Thiagalingam S, Wilcox M (2005). Genetics and epigenetics in major psychiatric disorders: dilemmas, achievements, applications, and future scope. Am J Pharmacogenomics 5: 149-160.

Albers LJ, Musenga A, Raggi MA (2008). Iloperidone: a new benzisoxazole atypical antipsychotic drug. Is it novel enough to impact the crowded atypical antipsychotic market? Expert Opin Investig Drugs 17: 61-75.

Altar CA, Amakye D, Bounos D, Bloom J, Clack G, Dean R et al (2008). A prototypical process for creating evidentiary standards for biomarkers and diagnostics. Clin Pharmacol Ther 83: 368-371.

Arranz MJ, de Leon J (2007). Pharmacogenetics and pharmacogenomics of schizophrenia: a review of the last decade of research. Mol Psychiatry 12: 707-747.

Arranz MJ, Munro J, Birkett J, Bolonna A, Mancama D, Sodhi M et al (2000a). Pharmacogenetic prediction of clozapine response. Lancet 355: 1615-1616.

Arranz MJ, Munro J, Osborne S, Collier DA, Kerwin RW (2000b). Difficulties in replication of results. Lancet 356: 1359-1360. 
Arranz MJ, Munro J, Sham P, Kirov G, Murray RM, Collier DA et al (1998). Metaanalysis of studies on genetic variation in 5-HT2A receptors and clozapine response. Schizophr Res 132: 93-99.

Baird AE (2006). The blood option: transcriptional profiling in clinical trials. Pharmacogenomics 7: 141-144.

Beverage JN, Sissung TM, Sion AM, Danesi R, Figg WD (2007). CYP2D6 polymorphisms and the impact on tamoxifen therapy. J Pharm Sci 96 2224-2231.

Binder EB, Salyakina D, Lichtner P, Wochnik GM, Ising M, Pütz B et al (2004). Polymorphisms in FKBP5 are associated with increased recurrence of depressive episodes and rapid response to antidepressant treatment. Nat Genet 36: 1319-1325.

Birkenaes AB, Birkeland Kl, Engh JA, Jonsdottir H, Ringen PA, Færden A et al (2008). Dyslipidemia independent of body mass in antipsychotic treated patients under real life conditions. J Clin Psychopharmacol 28: 132-137.

Black III JL, O'Kane DJ, Mrazek DA (2007). The impact of CYP allelic variation on antidepressant metabolism: a review. Expert Opin Drug Metab Toxicol 3: 21-31.

Botts S, Diaz FJ, Santoro V, Spina E, Muscatello MR, Cogollo M et al (2008). Estimating the effects of co-medications on plasma olanzapine concentrations by using a mixed model. Prog Neuropsychopharmacol Biol Psychiatry 32: 1453-1458.

Boulton DW, DeVane CL, Liston HL, Markowitz JS (2002). In vitro P-glycoprotein affinity for atypical and conventional antipsychotics. Life Sci 71: 163-169.

Bowden NA, Weidenhofer J, Scott RJ, Schall U, Todd J, Michie PT et al (2006). Preliminary investigation of gene expression profiles in peripheral blood lymphocytes in schizophrenia. Schizophr Res 82: 175-183.

Burczynski ME, Dorner AJ (2006). Transcriptional profiling of peripheral blood cells in clinical pharmacogenomic studies. Pharmacogenomics 7: 187-202.

Cai WM, Nikoloff DM, Pan RM, de Leon J, Fanti P, Fairchild M et al (2006). CYP2D6 genetic variations in healthy adults in psychiatric African-American subjects: implications for clinical practice and genetic testing. Pharmacogenomics $J$ 6: 343-350.

Cappell K, Arndt M, Carey J (2005). Drugs get smart. Business Week, September 5 , 76-85.

Chou WH, Yan FX, de Leon J, Barnhill J, Rogers T, Cronin M et al (2000). Extension of a pilot study: impact from the cytochrome P450 2D6 polymorphism on outcomes and costs associated with severe mental illness. J Clin Psychopharmacology 20: 246-251.

Collins FS, McKusick VA (2001). Implications of the human genome project for medical science. JAMA 285: 540-544.

Corominas $\mathrm{H}$, Baiget $\mathrm{M}$ (2004). Clinical utility of thiopurine $S$-methyltransferase genotyping. Am J Pharmacogenomics 4: 1-8

Court MH (2007). A pharmacogenomics primer. J Clin Pharmacol 47: 1087-1103.

Danzon P, Towse A (2002). The economics of gene therapy and of pharmacogenetics. Value Health 5: 5-13.

de Leon J (2006). The AmpliChip CYP450 Test: personalized medicine has arrived in psychiatry. Expert Rev Mol Diagn 6: 277-286.

de Leon J (2007). The crucial role of the therapeutic window in understanding the clinical relevance of the poor $v s$ the ultrarapid metabolizer phenotypes in subjects taking drugs metabolized by CYP2D6 and CYP2C19. J Clin Psychopharmacol 27: $241-245$

de Leon J (2008). Pharmacogenomic tests (letter). Science 321: 769.

de Leon J, Armstrong SC, Cozza KL (2005a). The dosing of atypical antipsychotics. Psychosomatics 46: 262-273.

de Leon J, Armstrong SC, Cozza KL (2008a). A preliminary attempt to personalize risperidone dosing using drug-drug interactions and genetics. Part I. Psychosomatics 49: 258-270.

de Leon J, Armstrong SC, Cozza KL (2008b). A preliminary attempt to personalize risperidone dosing using drug-drug interactions and genetics. Part II. Psychosomatics 49: 347-361.

de Leon J, Arranz MJ, Ruaño G (2008c). Products for pharmacogenetic testing in psychiatry: a review of features and clinical realities. Clin Lab Med (in press).

de Leon J, Correa JC, Ruaño G, Windemuth A, Arranz MJ, Diaz FJ (2008d). Exploring genetic variations that may be associated with the direct effects of some antipsychotics on lipid levels. Schizophr Res 98: 40-46.

de Leon J, Diaz FJ (2007). Planning for the optimal design of studies to personalize antipsychotic prescriptions in the post-CATIE era: The clinical and pharmacoepidemiological data suggest that pursuing the pharmacogenetics of metabolic syndrome complications (hypertension, diabetes mellitus and hyperlipidemia) may be a reasonable strategy. Schizophr Res 96: 185-197.

de Leon J, Armstrong SC, Cozza KL (2006b). Clinical guidelines for psychiatrists for the use of pharmacogenetic testing for CYP450 2D6 and CYP450 2C19. Psychosomatics 47: 75-85.

de Leon J, Susce MT, Murray-Carmichael E (2006a). The AmpliChip CYP450 Genotyping Test: integrating a new clinical tool. Mol Diagn Ther 10: 135-151. de Leon J, Susce MT, Pan RM, Fairchild M, Koch W, Wedlund PJ (2005b). The CYP2D6 poor metabolizer phenotype may be associated with risperidone adverse drug reactions and discontinuation. J Clin Psychiatry 66: 15-27.

de Leon J, Susce MT, Johnson M, Hardin M, Pointer L, Ruaño G et al (2007a). A clinical study of the association of antipsychotics with hyperlipidemia. Schizophr Res 92: 95-102.

de Leon J, Susce MT, Pan RM, Wedlund PJ, Orrego ML, Diaz FJ (2007b). A study of genetic (CYP2D6 and ABCB1) and environmental (drug inhibitors and inducers) variables that may influence plasma risperidone levels. Pharmacopsychiatry 40: 93-102.

Deeks JJ (2001). Systematic reviews of evaluations of diagnostic and screening tests. Br Med J 323: 157-162.

Diaz FJ, Santero V, Spina E, Cogollo M, Rivera TE, Botts S et al (2008). Estimating the size of the effects of co-medications on plasma clozapine concentrations using a model that controls for clozapine doses and confounding variables. Pharmacopsychiatry 41: 81-91.

Duggan M (2005). Do new prescription drugs pay for themselves? The case of second-generation antipsychotics. J Health Econ 24: 1-31.

Egmont-Petersen M, Talmon JL, Hasman A (1997). Robustness metrics for measuring the influence of additive noise on the performance of statistical classifiers. Int J Med Inform 46: 103-112.

El Ela AA, Hartter S, Schmitt U, Hiemke C, Spahn-Langguth H, Langguth P (2004). Identification of p-glycoprotein substrates and inhibitors among psychoactive compounds - implications for pharmacokinetics of selected substrates. J Pharm Pharmacol 56: 967-975.

Emens LA (2005). Trastuzumab: targeted therapy for the management of HER-2/ neu-overexpressing metastatic breast cancer. Am J Ther 12: 243-253.

Emery J, Hayflick S (2001). The challenge of integrating genetic medicine into primary care. BMJ 322: 1027-1030

Evaluation of Genomic Applications in Practice and Prevention (EGAPP) Working Group (2007). Recommendations from the EGAPP Working Group: testing for cytochrome P450 polymorphisms in adults with nonpsychotic depression treated with selective serotonin reuptake inhibitors. Genet Med 9: 819-825.

Fargher EA, Tricker K, Newman W, Elliott R, Roberts SA, Shaffer JL et al (2007). Current use of pharmacogenetic testing: a national survey of thiopurine methyltransferase testing prior to azathioprine prescription. J Clin Pharm Ther 32: $187-195$

Feinstein AR, Horwitz RI (1997). Problems in the 'evidence' of 'evidence-based medicine'. Am J Med 103: 529-535.

FDA (2005). Guidance for Industry: Pharmacogenomic data submission. http:// www.fda.gov/cder/guidance/6400fnl.pdf (Viewed in April 2008).

FDA (2008). In Vitro Diagnostic Multivariate Index Assays (IVDMIAs). http:// www.fda.gov/cdrh/oivd/guidance/1610.pdf (Viewed in April 2008).

Ferentz AE (2002). Integrating pharmacogenomics into drug development Pharmacogenomics 3: 453-467.

Fodor SP (1997). Massively parallel genomics. Science 277: 393-395.

Gaedigk A, Bradford LD, Marcucci KA, Leeder JS (2002). Unique CYP2D6 activity distribution and genotype-phenotype discordance in black Americans. Clin Pharmacol Ther 72: 76-89.

Genomas (2008). http://www.genomas.net/ (Viewed in April 2008).

Glatt SJ, Everall IP, Kremen WS, Corbeil J, Sásik R, Khanlou N et al (2005). Comparative gene expression analysis of blood and brain provides concurrent validation of SELENBP1 up-regulation in schizophrenia. Proc Natl Acad Sci USA 102: $15533-15538$.

Greenhalgh T (1997). Papers that report diagnostic or screening tests. Br Med J 315: 540-543.

Grossman I (2007). Routine pharmacogenetic testing in clinical practice: dream or reality? Pharmacogenomics 8: 1449-1459.

Grosse SD, Teutsch SM, Haddix AC (2007). Lessons from cost-effectiveness research for United States public health policy. Annu Rev Public Health 28 365-391.

Gurwitz D, Weizman A, Rehavi M (2003). Education: teaching pharmacogenomics to prepare future physicians and researchers for personalized medicine. Trends Pharmacol Sci 24: 122-125.

Gurwitz D, Lunshof JE, Dedoussis G, Flordellis CS, Fuhr U, Kirchheiner $\mathrm{J}$ et at (2005). Pharmacogenomics education: International Society of Pharmacogenomics recommendations for medical, pharmaceutical, and health schools deans of education. Pharmacogenomics J 5: 221-225.

Hesselink JM (2002). Iloperidone (Novartis). IDrugs 5: 84-90.

Honigfeld G, Arellano F, Sethi J, Bianchini A, Schein J (1998). Reducing clozapinerelated morbidity and mortality: 5 years of experience with the Clozaril National Registry. J Clin Psychiatry 59(Suppl 3): 3-7.

Ingelman-Sundberg M, Daly AK, Nebert DW (eds) (2008). Home Page of the Human Cytochrome P450 (CYP) Allele Nomenclature Committee http:// www.cypalleles.ki.se (Viewed in April 2008). 
Ingelman-Sundberg M, Sim SC, Gomez A, Rodriguez-Antona C (2007). Influence of cytochrome P450 polymorphisms on drug therapies: pharmacogenetic, pharmacoepigenetic and clinical aspects. Pharmacol Ther 116: 496-526.

Javitt GH (2007). In search of a coherent framework. Options for FDA oversight of genetic tests. Food Drug Law J 62: 617-652.

Johnson M, Markham-Abedi C, Susce MT, Murray-Carmichael E, McCollum S, de Leon J (2006). A poor metabolizer for both cytochrome P450 2D6 and 2C19 (CYP2D6 and CYP2C19): a case report on antidepressant treatment. CNS Spectrums 11: 757-760.

Justice AC, Covinsky KE, Berlin JA (1999). Assessing the generalizability of prognostic information. Ann Intern Med 130: 515-524.

Katsanis SH, Javitt G, Hudson K (2008). A case study of personalized medicine. Science 320: 53-54.

Kim SF, Huang AS, Snowman AM, Teuscher C, Snyder SH (2007). Antipsychotic drug-induced weight gain mediated by histamine $\mathrm{H}_{1}$ receptor-linked activation of hypothalamic AMP-kinase. Proc Natl Acad Sci USA 104: 3456-3459.

Kirchheiner J, Nickchen K, Bauer M, Wong M-L, Licinio J, Roots I et al (2004). Pharmacogenetics of antidepressants and antipsychotics: the contribution of allelic variations to the phenotype of drug response. Mol Psychiatry 9: 442-473.

Kirkwood SC, Hockett Jr RD (2002). Pharmacogenomic biomarkers. Dis Markers 18: $63-71$.

Koch WH (2004). Technology platforms for pharmacogenomic diagnostic assays. Nat Rev Drug Discov 3: 749-761.

Lavedan C, Licamele L, Volpi S, Hamilton J, Heaton C, Mack K et al (2008a). Association of the NPAS3 gene and five other loci with response to the antipsychotic iloperidone identified in a whole genome association study. $\mathrm{Mol}$ Psychiatry, e-pub ahead of print.

Lavedan C, Volpi S, Polymeropoulos MH, Wolfgang CD (2008b). Effect of a ciliary neurotrophic factor polymorphism on schizophrenia symptom improvement in an iloperidone clinical trial. Pharmacogenomics 9: 289-301.

Lertola $J$ (1999). Deciphering the code and what might come from it. Time, November 8, 68-69.

Lesko LJ, Atkinson Jr AJ (2001). Use of biomarkers and surrogate endpoints in drug development and regulatory decision making: criteria, validation, strategies. Annu Rev Pharmacol Toxicol 41: 347-366.

LGC (2008). Clozapine response test: pharmacogenetics in psychiatry. http:// www.lgc.co.uk/service.asp?intElement $=6314$ (Viewed in April 2008).

Lieberman JA, Yunis J, Egea E, Canoso RT, Kane Jm, Yunis EY (1990). HLA-B38, DR4, DQw3 and clozapine-induced agranulocytosis in Jewish patients with schizophrenia. Arch Gen Psychiatry 47: 945-948.

Luminex (2008). What is xTag technology? http://www.luminexcorp.com/technology/xtag/index.html (Viewed in April 2008).

Malhotra A.K, Athanasiou M, Reed CR, Dain B, Carr J, Whalen H et al (2005). Discovery of genetic markers associated with clozapine induced agranulocytosis. Am J Med Gen Part B Neuropsychiatr Genet 138b: 22.

Mallal S, Phillips E, Carosi G, Molina JM, Workman C, Tomazic J, et al, Benbow A for the PREDICT-1 study team (2008). HLA-B`5701 screening for hypersensitivity to abacavir. N Engl J Med 358: 568-579.

Markham-Abedi C, de Leon J (2006). Hypertriglyceridemia associated with direct effects of olanzapine rather than with weight gain: a case report (letter). J Clin Psychiatry 67: 1473-1474.

Marsh S (2007). Pyrosequencing applications. Methods Mol Biol 373: 15-24.

Mayo Clinic Laboratory. http://mayomedicallaboratories.com (Viewed in March 2008).

McEvoy JP, Meyer JM, Goff DC, Nasrallah HA, Davis SM, Sullivan L et al (2005). Prevalence of the metabolic syndrome in patients with schizophrenia: Baseline results from the Clinical Antipsychotic Trials of Intervention Effectiveness (CATIE) schizophrenia trial and comparison with national estimates from NHANES III. Schizophr Res 80: 19-32.

McKusick VA (2001). The anatomy of the human genome: a neo-vesalian basis for medicine in the 21st century. JAMA 286: 2289-2295.

McMahon FJ, Buervenich S, Charney D, Lipsky R, Rush AJ, Wilson AF et al (2006). Variation in the gene encoding the serotonin $2 \mathrm{~A}$ receptor is associated with outcome of antidepressant treatment. Am J Hum Genet 78: 804-814.

Melis R, Lyon E, McMillin GA (2006). Determination of CYP2D6, CYP2C9 and CYP2C19 genotypes with Tag-It ${ }^{\mathrm{TM}}$ mutation detection assays. Expert Rev Mol Diagn 6: 811-820.

Meyer JM, Koro CE (2004). The effects of antipsychotic therapy on serum lipids: A comprehensive review. Schizophr Res 70: 1-17.

Nebert DW, Zhang G, Vesell ES (2008). From human genetics and genomics to pharmacogenetics and pharmacogenomics: past lessons, future directions. Drug Metab Rev 40: 187-224.
Newcomer JW, Haupt DW (2006). The metabolic effects of antipsychotic medications. Can J Psychiatry 51: 480-491.

Nnadi CU, Malhotra AK (2008). Clinical and pharmacokinetic studies of iloperidone. Personalized Med 5: 367-375.

Orr MS, Goodsaid F, Amur S, Rudman A, Frueh FW (2007). The experience with voluntary genomic data submissions at the FDA and a vision for the future of the voluntary data submission program. Clin Pharmacol Ther 81: 294-297.

Ouahchi K, Lindeman N, Lee C (2006). Copy number variants and pharmacogenomics. Pharmacogenomics 7: 25-29.

Paddock S, Laje G, Charney D, Rush AJ, Wilson AF, Sorant AJ et al (2007). Association of GRIK4 with outcome of antidepressant treatment in the STAR*D cohort. Am J Psychiatry 164: 1181-1188.

Pathway Diagnostics http://www.pathwaydx.com/proprietary/biomarker_portfolio. php (Viewed in March 2008).

Perlis RH, Ganz DA, Avorn J, Schneeweiss S, Glynn RJ, Smoller JW et al (2005). Pharmacogenetic testing in the clinical management of schizophrenia: a decision-analytic model. J Clin Psychopharmacol 25: 427-434.

Perlis RH, Moorjani P, Fagerness J, Purcell S, Trivedi MH, Fava M et al (2008). Pharmacogenetic Analysis of Genes Implicated in Rodent Models of Antidepressant Response: Association of TREK1 and Treatment Resistance in the STAR $\left.^{*}\right)$ D Study. Neuropsychopharmacology e-pub 20 February 2008.

Peters EJ, Slager SL, Kraft JB, Jenkins GD, Reinalda MS, McGrath PJ et al (2008). Pharmacokinetic genes do not influence response or tolerance to citalopram in the STAR ${ }^{\star} \mathrm{D}$ sample. PLOS ONE 3: e1872.

PgxHealth (2008). http://www.pgxhealth.com/genetictests (Viewed in April 2008).

Phillips KA, Veenstra DL, Oren E, Lee JK, Sadee W (2001). Potential role of pharmacogenomics in reducing adverse drug reactions: a systematic review. JAMA 286: 2270-2279.

Pirmohamed M (2001). Pharmacogenetics and pharmacogenomics. J Clin Pharmacol 52: 345-347.

Redon R, Ishikawa S, Fitch KR, Feuk L, Perry GH, Andrews TD et al (2006). Global variation in copy number in the human genome. Nature 444: 444-454.

Reist C, Mintz J, Albers LJ, Mintz J, Albers LJ, Jamal MM et al (2007). Secondgeneration antipsychotic exposure and metabolic-related disorders in patients with schizophrenia: an observational pharmacoepidemiology study from 1988 to 2002. J Clin Psychopharmacol 27: 46-51.

Rembold CM (1998). Number needed to screen: development of a statistic for disease screening. BMJ 317: 307-312.

Roche (2008). AmpliChip CYP450 Test. http://www.roche.com/home/products/ prod_diag_amplichip.htm (Viewed in April 2008).

Roses AD (2004). Pharmacogenetics and drug development: the path to safer and more effective drugs. Nat Rev 5: 645-656.

Ruaño G (2004). Quo vadis personalized medicine. Personalized Med 1: 1-7.

Ruaño G, Blair CL, Bower B, Windemuth A, Kocherla M, Aleman Y et al (2007a). Somatic complications of psychotropic medication in a patient with multiple CYP2 drug metabolism deficiencies. Conn Med 71: 197-200.

Ruaño G, Goethe JW, Caley C, Woolley S, Holford TR, Kocherla M et al (2007b). Physiogenomic comparison of weight profiles of olanzapine- and risperidonetreated patients. Mol Psychiatry 12: 474-482.

Ruaño G, Makowski G, Windemuth A, Kocherla M, Weiss S, Goethe JW et al (2006). High carrier prevalence of deficient and null alleles of CYP2 genes in a major USA hospital: implications for personalized drug safety. Personalized Med 3: 131-137.

Sabbagh A, Génin E, Darlu P (2008). Selecting predictive markers for pharmacogenetic traits: tagging $v s$ data-mining approaches. Hum Hered 66: 10-18.

Sadee W (2002). Pharmacogenomics: the implementation phase. AAPS Newsmag, April, 14-35.

Salerno RA, Lesko LJ (2005). Pharmacogenomics data: FDA voluntary and required submission guidance. Pharmacogenomics 5: 503-505.

Scherzer CR, Eklund AC, Morse LJ, Liao Z, Locascio JJ, Fefer D et al (2007). Molecular markers of early Parkinson's disease based on gene expression in blood. Proc Natl Acad Sci USA 104: 955-960.

Schumacher J, Schulze TG, Wienker TF, Rietschel M, Nothen MM (2000). Pharmacogenetics of the clozapine response. Lancet 356: 506-507.

Science (1997). New research horizons. Science 278: 2039.

Scott SA, Edelmann L, Kornreich R, Erazo M, Desnick RJ (2007). CYP2C9, CYP2C19 and CYP2D6 allele frequencies in the Ashkenazi Jewish population. Pharmacogenomics 8: 721-730.

Sebat J, Lakshmi B, Malhotra D, Troge J, Lese-Martin C, Walsh T et al (2007). Strong association of de novo copy number mutations with autism. Science 316 : 445-449.

Segman RH, Shefi N, Goltser-Dubner T, Friedman N, Kaminski N, Shalev AY (2005). Peripheral blood mononuclear cell gene expression profiles identify emergent 
post-traumatic stress disorder among trauma survivors. Mol Psychiatry 10: 500-513.

Sendtner M, Carroll P, Holtmann B, Hughes RA, Thoenen H (1994). Ciliary neurotrophic factor. J Neurobio/ 25: 1436-1453.

Serretti A, Artioli $P$ (2004). The pharmacogenomics of selective serotonin reuptake inhibitors. Pharmacogenomics J 4: 233-244.

Serretti A, Kato M, De Ronchi D, Kinoshita T (2007). Meta-analysis of serotonin transporter gene promoter polymorphism (5-HTTLPR) association with selective serotonin reuptake inhibitor efficacy in depressed patients. Mol Psychiatry 12 247-257.

Sharma RP, Rosen C, Kartan S, Guidotti A, Costa E, Grayson DR et al (2006). Valproic acid and chromatin remodeling in schizophrenia and bipolar disorder: preliminary results from a clinical population. Schizophr Res $\mathbf{8 8}$ 227-231.

Sim SC, Risinger C, Dahl ML, Akilillu E, Christensen M, Bertilsson L et al (2006). A common novel CYP2C19 gene variant causes ultrarapid drug metabolism relevant for the drug response to proton pump inhibitors and antidepressants. Clin Pharmacol Ther 79: 103-113.

Steemers FJ, Gunderson KL (2007). Whole genome genotyping technologies on the BeadArray platform. Biotechnol J 2: 41-49.

Stroup TS, Lieberman JA, McEvoy JP, Swartz MS, Davis SM, Capuano GA, et al, CATIE Investigators (2007). Effectiveness of olanzapine, quetiapine, and risperidone in patients with chronic schizophrenia after discontinuing perphenazine: a CATIE study. Am J Psychiatry 164: 415-427.

Suarez-Kurtz G, Pena SD (2006). Pharmacogenomics in the Americas: the impact of genetic admixture. Curr Drug Targets 7: 1649-1658.

Susce MT, Villanueva N, Diaz FJ, de Leon J (2005). Obesity and associated complications in patients with severe mental illnesses: a cross-sectional survey. J Clin Psychiatry 66: 167-173.

Swanson BN (2002). Delivery of high-quality biomarker assays. Dis Markers 18 : 47-56.

Tolosano E, Cutufia MA, Hirsch E, Stefanuto G, Voyron S, Fasolo A et al (1996). Ciliary neurotrophic factor constitutively expressed in the nervous system of transgenic mice protects embryonic dorsal root ganglion neurons from apoptosis. Eur J Neurosci 8: 521-529.

Touw DJ, Neef C, Thomson AH, Vinks AA, Cost-Effectiveness of Therapeutic Drug Monitoring Committee of the International Association for Therapeutic Drug Monitoring and Clinical Toxicology (2005). Cost-effectiveness of therapeutic drug monitoring: a systematic review. Ther Drug Monit 27: 10-17.

The Secretary's Advisory Committee on Genetics, Health and Society (SACGHS) (2006). Coverage and reimbursement of genetic tests and services. http:// www4.od.nih.gov/oba/sacghs/reports/CR report.pdf (Viewed in April 2008).

Trenti T (2003). Evidence-based laboratory medicine as a tool for continuous professional improvement. Clin Chim Acta 333: 155-167.
Tsuang MT, Nossova N, Yager T, Tsuang MM, Guo SC, Shyu KG et al (2005). Assessing the validity of blood-based gene expression profiles for the classification of schizophrenia and bipolar disorder: A preliminary report. Am J Med Genet B Neuropsychiatr Genet 133: 1-5.

Uhr M, Tontsch A, Namendorf C, Ripke S, Lucae S, Ising M et al (2008). Polymorphisms in the drug transporter gene ABCB1 predict antidepressant treatment response in depression. Neuron 57: 203-209.

Vanda Pharmaceuticals (2008). Vanda Pharmaceuticals announce receipt of not approvable letter from FDA for iloperidone. http://phx.corporate-ir.net/ phoenix.zhtml?c=196233\&p = irol-newsArticle_print\&ID = 1179851\&highlight = (Viewed in September 2008).

Van den Bruel A, Cleemput I, Aertgeerts B, Ramaekers D, Buntinx F (2007). The evaluation of diagnostic tests: evidence on technical and diagnostic accuracy, impact on patient outcome and cost-effectiveness is needed. J Clin Epidemio 60: 1116-1122.

Vogel F (1959). Moderne probleme der Humangenetik. Ergeb Inn Med Kinderheild 12: $52-125$

Volpi S, Heaton C, Mack K, Hamilton JB, Lannan R, Wolfgang CD et al (2008). Whole genome association study identifies polymorphisms associated with QT prolongation during iloperidone treatment of schizophrenia. Mol Psychiatry. epub ahead of print.

Wagner JA (2002). Overview of biomarkers and surrogate endpoints in drug development. Dis Markers 18: 41-46.

Wagner JA (2008). Strategic approach to fit-for-purpose biomarkers in drug development. Annu Rev Pharmacol Toxicol 48: 631-651.

Walsh T, McClellan JM, McCarthy SE, Addington AM, Pierce SB, Cooper GM et al (2008). Rare structural variants disrupt multiple genes in neurodevelopmental pathways in schizophrenia. Science 320: 539-543.

Wang JS, Ruan Y, Taylor RM, Donovan JL, Markowitz JS, DeVane CL (2004). The brain entry of risperidone and 9-hydroxyrisperidone is greatly limited by p-glycoprotein. Int J Neuropsychopharmacology 7: 415-419.

Wang Y, Krishnan HR, Ghezzi A, Yin JCP, Atkinson NS (2007). Drug-induced epigenetic changes produce drug tolerance. PLoS Biol 5: e265.

Wedlund PJ (2000). The CYP2C19 enzyme polymorphism. Pharmacology 6 174-185.

Wedlund PJ, de Leon J (2001). Pharmacogenetic testing: the cost factor Pharmacogenomics J 1: 171-174.

Weinshilboum R, Wang $L$ (2004). Pharmacogenomics: bench to bedside. Nat Rev 3: 739-748.

Wennerholm A, Dandara C, Sayi J, Svensson JO, Abdi YA, Ingelman-Sundberg M et al (2002). The African-specific CYP2D6*17 allele encodes an enzyme with changed substrate specificity. Clin Pharmacol Ther 71: 77-88.

Wolf CR, Smith G, Smith RL (2000). Science, medicine, and the future: pharmacogenetics. BMJ 320: 987-990. 